\title{
Clinical courses after administration of oral corticosteroids in patients with severely cholestatic acute hepatitis $A$; three cases
}

\author{
Eileen L. Yoon ${ }^{1}$, Hyung Joon Yim${ }^{1}$, Seung Young Kim¹, Jeong Han Kim¹, Ju-Han Lee ${ }^{2}$, \\ Young Sun Lee ${ }^{1}$, Hyun Jung Lee ${ }^{1}$, Sung Woo Jung ${ }^{1}$, Sang Woo Lee ${ }^{1}$, Jai Hyun Choi ${ }^{1}$ \\ ${ }^{1}$ Division of Gastroenterology and Hepatology, Department of Internal Medicine and ${ }^{2}$ Department of Pathology, \\ Korea University College of Medicine, Seoul, Korea
}

\begin{abstract}
Acute hepatitis $A$ is currently outbreaking in Korea. Although prognosis of acute hepatitis $A$ is generally favorable, a minority of patients are accompanied by fatal complications. Severe cholestasis is one of the important causes of prolonged hospitalization in patients with acute hepatitis A. In such cases, higher chances of additional complications and increased medical costs are inevitable. We report three cases of severely cholestatic hepatitis A, who showed favorable responses to oral corticosteroids. Thirty milligram of prednisolone was initiated and tapered according to the responses. Rapid improvement was observed in all cases without side effects. We suggest that corticosteroid administration can be useful in hepatitis A patients with severe cholestasis who do not show improvement by conservative managements. Clinical trial will be needed to evaluate effectiveness of corticosteroids in these patients. (Korean J Hepatol 2010;16:329-333)
\end{abstract}

Keywords: Acute hepatitis A; Cholestasis; Corticosteroid

\section{INTRODUCTION}

The incidence of acute viral hepatitis A is continuously increasing in Korea recently. ${ }^{1}$ Patients present with fever, anorexia, nausea, vomiting, or jaundice, and frequently need hospitalization. The clinical course of acute hepatitis A is usually benign, and it is known that symptomatic treatment is sufficient for recovery. ${ }^{2}$ However, in rare cases, acute hepatitis A can be associated with serious complications which require prolonged hospitalization, and may result in death or liver transplantation. ${ }^{3}$ Cholestatic hepatitis is one of atypical clinical manifestations of acute viral hepatitis. Although it occurs only at a rate of $0.4 \sim 0.8 \%$, protracted symptoms of anorexia, weight loss, pruritus, and jaundice are commonly associated. ${ }^{3}$ These clinical situations prolong the length of hospital stay, which causes increased medical expenses and social costs.
It has been presented that there had been a rapid improvement of the clinical symptoms and signs in a patient with cholestatic hepatitis A after use of steroid. ${ }^{4}$ However, there is no detailed information on the progress of the patient.

We recently experienced three cases of acute hepatitis A with severe cholestasis, whose serum bilirubin was promptly decreased following administration of steroid. Herein, we report our cases with detailed description of clinical courses and review of literatures.

\section{CASE REPORT}

Three patients were referred to Korea University Ansan Hospital for admission under the impression of acute hepatitis. The patients denied history of taking any medicines, excessive drinking, and presence of chronic liver disease. Serologic tests

Received March 24, 2010; Revised June 15, 2010; Accepted July 22, 2010

Abbreviations: ALP, alkaline phosphatase; ALT, alanine aminotransferase; AST, aspartate aminotransferase; HBsAg, hepatitis B surface antigen; $\mathrm{HCV}$, Hepatitis $\mathrm{C}$ virus; IgM anti-HAV, immunoglobulin $\mathrm{M}$ antibody to hepatitis A virus; IgM anti-HBc, immunoglobulin $\mathrm{M}$ antibody to hepatitis B core antigen; IgM anti-HEV Ab, immunoglobulin M antibody to hepatitis E virus; $\gamma$-GT, gamma-glutamyl transferase; mrp, multidrug resistance-associated protein; WBC, white blood cell

Comesponding author: Hyung Joon Yim

Department of Internal Medicine, Korea University Ansan Hospital, 516 Gojan-dong, Danwon-gu, Ansan 425-707, Korea

Tel. +82-31-412-6565, Fax. +82-31-412-5582, E-mail; gudwns21@medimail.co.kr 
showed negative responses to hepatitis B surface antigen (HBsAg), IgM antibody to hepatitis B cores antigen (IgM anti-HBc), hepatitis $\mathrm{C}$ antibody (HCV Ab), and IgM antibody to hepatitis E virus (IgM anti-HEV), while positive immunereactivity to IgM antibody to hepatitis A virus (IgM anti-HAV) was observed, in all patients. On the basis of the history and the laboratory findings, acute viral hepatitis A was diagnosed. Supportive treatment with ursodeoxycholic acid, silymarin and intravenous fluid was done. However, sustained increase of serum bilirubin was observed. Possibility of obstructive jaundice was ruled out based on abdominal ultrasonography or CT scan. To exclude the possibility of infiltrative liver disease or small bile duct injury, liver biopsy was performed. On histopathologic examination, moderate to severe inflammatory cell infiltration was observed surrounding hepatic lobules and portal veins. Portal or periportal fibrosis and intracellular cholestasis were also found (Fig. 1). However there was no bile ductular lesion. Despite long-term conservative therapy, there was no significant improvement of the clinical features with persistence of hyperbilirubinemia. We started steroid therapy for the reversal of prolonged cholestasis. Possibility of the systemic infection other than viral hepatitis A was ruled out by absence of fever, leukocytosis, any abnormalities on chest X-ray, and pyuria. Prednisolone $30 \mathrm{mg}$ was administered until serum bilirubin fell below the half level of baseline value. Thereafter, dose of steroid was tapered at intervals of two weeks and its administration was discontinued after 6-10 weeks (Table 1).

The more detailed clinical information of the individual cases is described on the followings.

\section{Case 1}

A 40-year-old man visited with complaints of general weakness for a week and jaundice for three days. His vital signs were stable, blood pressure of 140/100 mmHg, pulse rates of 94 beats/minute, respiration rates of $20 /$ minute and body temperature of $36^{\circ} \mathrm{C}$ on the visit. He looked acutely ill with icteric sclerae. Abdominal examinations revealed tenderness on right upper quadrant area. Hepatosplenomegaly was not noted. Neither
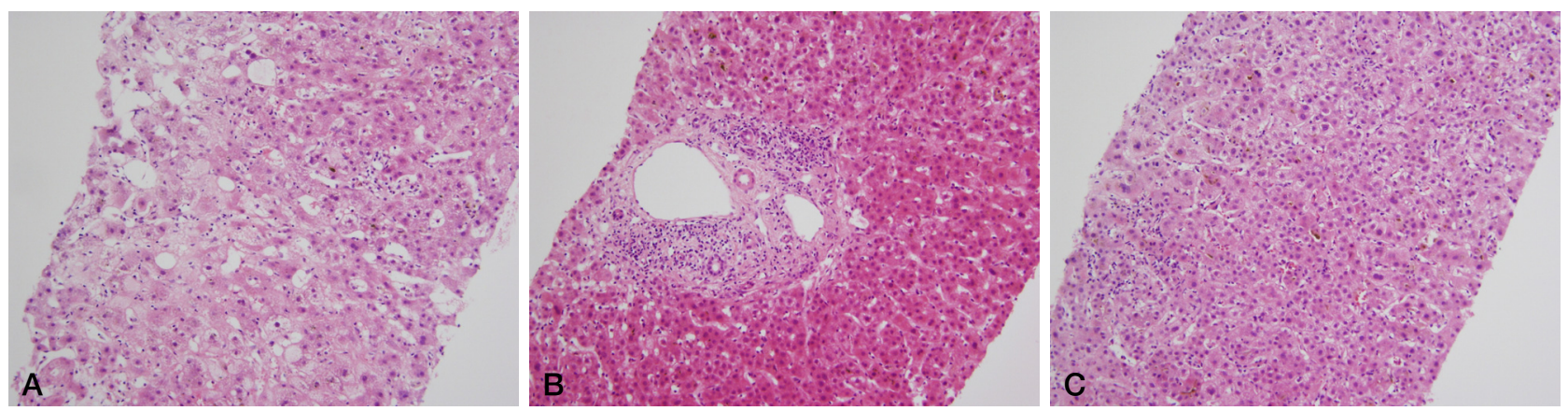

Figure 1. Microscopic findings show moderate to severe inflammatory activity and intrahepatic cholestases without ductular destruction. (A) Hepatocyte ballooning and severe inflammation of the portal tracts with periportal fibrosis are noted (case $1, \mathrm{H} \& \mathrm{E} \times 200)$. (B) Moderate inflammation with mild portal fibrosis is noted (case 2, H\&E $\times 200$ ). (C) Intrahepatic cholestasis and severe lobular inflammation with periportal fibrosis are noted (case 3, H\&E×200).

Table 1. Demographic data and clinical courses of the patients with cholestatic hepatitis A

\begin{tabular}{|c|c|c|c|}
\hline Case & 1 & 2 & 3 \\
\hline Age (yr) & 40 & 35 & 42 \\
\hline Peak serum ALT (IU/L) & 7,090 & 163 & 118 \\
\hline Peak serum total bilirubin $(\mathrm{mg} / \mathrm{dL})$ & 23.5 & 31.79 & 31.5 \\
\hline Pre-prednisolone treatment serum ALT (IU/L) & 158 & 59 & 35 \\
\hline Pre-prednisolone treatment serum total bilirubin $(\mathrm{mg} / \mathrm{dL})$ & 19.8 & 27.97 & 31.5 \\
\hline Hospital days before administration of prednisolone (day) & 28 & $30^{*}$ & $43^{\dagger}$ \\
\hline Time to discharge after prednisolone use (day) & 14 & 27 & 13 \\
\hline Time to decrease below the half level of pretreatment bilirubin (day) & 13 & 23 & 8 \\
\hline Time to normalization of serum bilirubin (day) & 55 & 82 & 60 \\
\hline
\end{tabular}

* This includes admission periods of 20 days at a local hospital for symptomatic treatment.

$\uparrow$ This includes admission periods of 25 days at a local hospital for symptomatic treatment. 


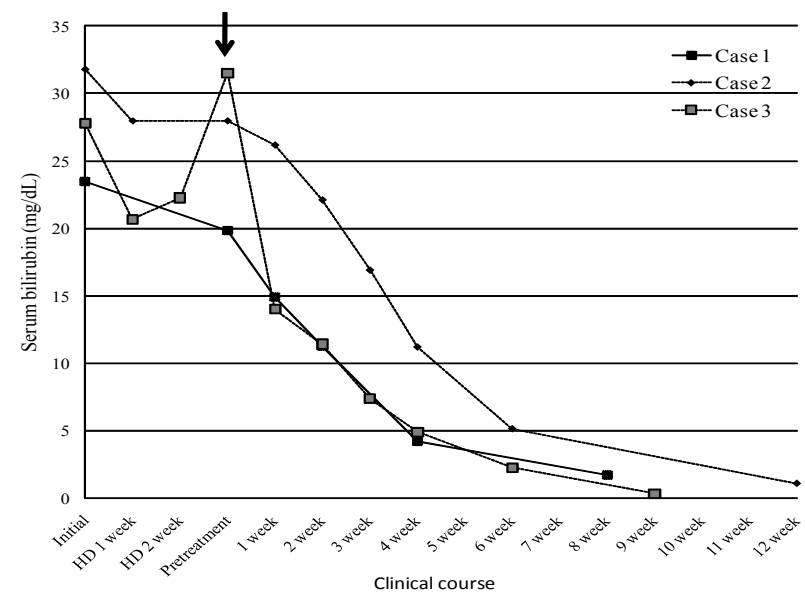

Figure 2. Responses to steroids in individual subjects. Immediate declines of serum total bilirubin levels are noted after initiation of oral prednisolone. Black arrows indicate the time point when prednisolone was started.

pitting edema on extremities nor any neurologic abnormalities were found. On laboratory findings, complete blood count

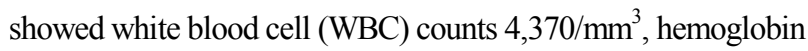
$17.3 \mathrm{~g} / \mathrm{dL}$, platelets $101,000 / \mathrm{mm}^{3}$ and his prothrombin time international normalized ratio (INR) was 1.64. On serum biochemistry, the patient showed total bilirubin $23.5 \mathrm{mg} / \mathrm{dL}$, direct bilirubin $12.4 \mathrm{mg} / \mathrm{dL}$, AST 5,558 IU/L, ALT 7,090 IU/L, ALP $75 \mathrm{IU} / \mathrm{L}$ and gamma-glutamyl transpeptidase $(\gamma-\mathrm{GT}) 456$ IU/L. Transient elastography measured the liver stiffness as high as $28.8 \mathrm{kPa}$. Finally acute viral hepatitis A was diagnosed and he was treated symptomatically. On week 4, although AST and ALT levels decreased to $173 \mathrm{IU} / \mathrm{L}$ and $152 \mathrm{IU} / \mathrm{L}$, respectively, total bilirubin was still as high as $19.8 \mathrm{mg} / \mathrm{dL}$ with direct bilirubin of $11.5 \mathrm{mg} / \mathrm{dL}$. Also, cholestasis maintained, with complaints of severe pruritus, anorexia, and body weight loss. The patient started prednisolone at a dose of $30 \mathrm{mg} /$ day. On the $13^{\text {th }}$ day of prednisolone administration, total and direct bilirubin decreased to $11.3 \mathrm{mg} / \mathrm{dL}$ and $6.1 \mathrm{mg} / \mathrm{dL}$ respectively with improvement of generalized symptoms, and he discharged. After 4 weeks following the administration of prednisolone, it was tapered off by $10 \mathrm{mg}$ at intervals of two weeks. On the $8^{\text {th }}$ weeks, total bilirubin decreased to $1.7 \mathrm{mg} / \mathrm{dL}$ (Fig. 2). Liver stiffness on transient elastography became normalized to $3.6 \mathrm{kPa}$.

\section{Case 2}

A 35-year-old man diagnosed with acute hepatitis A was referred to our hospital after 2-weeks of hospitalization in the other hospital. On admission, his vital signs were stable. He looked acutely ill and icteric, but was in a clear mental status. On abdominal examination, a finger breadth of liver was palpable with mild tenderness in right upper quadrant area. No peripheral edema on extremities was found. On laboratory findings, complete blood count showed WBC counts $4,960 / \mathrm{mm}^{3}$, hemoglobin 14.7 $\mathrm{g} / \mathrm{dL}$, platelets $420,000 / \mathrm{mm}^{3}$ and prothrombin time INR 0.94 . On serum biochemistry, the patient showed total bilirubin 31.79 $\mathrm{mg} / \mathrm{dL}$, direct bilirubin $17.3 \mathrm{mg} / \mathrm{dL}$, AST $45 \mathrm{IU} / \mathrm{L}$, ALT $53 \mathrm{IU} / \mathrm{L}$, ALP $253 \mathrm{IU} / \mathrm{L}$ and $\gamma$-GT $309 \mathrm{IU} / \mathrm{L}$. Transient elastography measured the liver stiffness as $14.1 \mathrm{kPa}$. Despite additional 2-weeks of conservative therapy at our hospital, total and direct bilirubin were still elevated up to $27.97 \mathrm{mg} / \mathrm{dL}$ and $16.28 \mathrm{mg} / \mathrm{dL}$, respectively. Jaundice and malaise persisted. Liver biopsy was done and prednisolone was initiated at a dose of $30 \mathrm{mg}$. On the $23^{\text {rd }}$ day following administration of steroid, total and direct bilirubin declined to $13.2 \mathrm{mg} / \mathrm{dL}$ and $6.8 \mathrm{mg} / \mathrm{dL}$. After 4 weeks of prednisolone therapy, it was tapered by $10 \mathrm{mg}$ at intervals of two weeks and stopped after 12 weeks of administration. Total and direct bilirubin decreased to $1.09 \mathrm{mg} / \mathrm{dL}$ (Fig. 2). Liver stiffness declined to $7.0 \mathrm{kPa}$ on transient elastography.

\section{Case 3}

A 42-year-old man, who had fever and nausea, received a diagnosis of acute hepatitis A at a local clinic. The patient was referred to us after 4-weeks of in-hospital treatment. His vital signs were stable. He was in a clear mental status, with icteric sclerae. Abdominal examination revealed mild right upper quadrant tenderness. Peripheral edema was not noted on extremities. On laboratory findings, complete blood count showed WBC counts $6,710 / \mathrm{mm}^{3}$, hemoglobin $12.6 \mathrm{~g} / \mathrm{dL}$, platelets $434,000 / \mathrm{mm}^{3}$ and his prothrombin time INR 1.08 . On serum biochemistry, the patient showed total bilirubin 27.8 mg/dL, direct bilirubin $14.8 \mathrm{mg} / \mathrm{dL}$, AST 475 IU/L, ALT 104 IU/L, ALP $121 \mathrm{IU} / \mathrm{L}$ and $\gamma$-GT $57 \mathrm{IU} / \mathrm{L}$. Liver stiffness was measured as $23.4 \mathrm{kPa}$ on transient elastography. Despite additional 3-weeks of conservative treatment, pruritus persisted, and appetite was decreased with significant body weight loss. On laboratory finding, total and direct bilirubin peaked up to 31.5 $\mathrm{mg} / \mathrm{dL}$ and $14.8 \mathrm{mg} / \mathrm{dL}$, while AST and ALT were decreasing to $59 \mathrm{IU} / \mathrm{L}$ and $30 \mathrm{IU} / \mathrm{L}$, respectively. This led to biopsy of liver, after which $30 \mathrm{mg}$ of prednisolone was administered. On $8^{\text {th }}$ day of prednisolone, total and direct bilirubin were rapidly decreasing to $13.99 \mathrm{mg} / \mathrm{dL}$ and $7.73 \mathrm{mg} / \mathrm{dL}$, respectively. Liver stiffness declined to $20.1 \mathrm{kPa}$ on $10^{\text {th }}$ day with the improvement of generalized symptoms. The patient discharged and prednisolone was tapered at intervals of two weeks by $10 \mathrm{mg}$ at outpatient 
clinic. Nine weeks after steroid treatment, total bilirubin decreased to $0.32 \mathrm{mg} / \mathrm{dL}$ (Fig. 2).

\section{DISCUSSION}

Hepatitis A is a self-limited disease and is not associated with chronicity. Clinical presentations are more severe with increasing age, so adults are more frequently associated with prolonged jaundice compared to children. The genotype of the viral hepatitis A is also reported to affect the severity of the cholestasis. ${ }^{5}$ However, exact causes of prolonged cholestasis are unknown. Recently, the prevalence of its protective antibody has been decreasing in adolescents and adults in Korea. According to this, there is a tendency that mean age of patients with hepatitis $A$ is gradually increasing. Therefore, it is expected that the number of patients who show severe clinical manifestation including prolonged cholestasis would increase. ${ }^{1}$ Although presence of persistent cholestasis can still be managed symptomatically, this frequently lengthens hospital stay and causes medical expenses and socioeconomic loss. Therefore it is imperative that the methods be developed to improve clinical courses more promptly in patients with acute viral hepatitis A complicated by persistent uncontrolled cholestasis. Our report suggests that corticosteroid therapy is effective in these patients.

Cholestasis can result from any defects in the step of the bilirubin metabolism; decreased uptake of bilirubin, impaired conjugation in the hepatocytes, disorders of bile excretion into biliary system, or obstruction of bile ducts may involve. Cholestasis accompanied by viral hepatitis A is mainly based on inflammatory responses. It is developed by the systemic and intrahepatic release of endotoxin (lipopolysaccharide) and pro-inflammatory cytokines including tumor necrosis factor- $\alpha$ (TNF- $\alpha$ ) or interleukin-1 (IL-1). ${ }^{6}$ It is therefore conceivable that cholestasis associated with this inflammatory process can be improved by the administration of steroids. It is known that multidrug resistance-associated protein 2 (mrp2), a transporter protein which is involved in excretion of the bilirubin outside the hepatocytes during the steps of bilirubin metabolism, is inhibited by TNF- $\alpha$ and IL-1. ${ }^{7}$ Dexamethasone inhibits the synthesis of TNF- $\alpha$ and IL-1, and thereby prevents impairment of the function of mrp2 in the canaliculi of endotoxemic rats. ${ }^{8}$ In addition, there are several glucocorticoid responsive elements on the promoter region of the mrp2 gene, ${ }^{9}$ so dexamethasone induces the expression of mrp2 twice as much even in normal liver tissue and facilitates the metabolism of the bilirubin. ${ }^{10}$ It was reported that a short course of corticosteroids therapy resulted in a rapid decline of serum bilirubin levels and relief of pruritus in approximately two-thirds of patients with acute cholestatic viral hepatitis. ${ }^{11}$ However, there are also several contradictory reports that steroid therapy does not affect the clinical course or prognosis in patients with acute hepatitis with cholestasis. A prospective study conducted in 1981 with 77 acute viral hepatitis patients reported that there was no advantage with the use of corticosteroids early in the course of severe viral hepatitis. ${ }^{12}$ It was also reported that cholestasis spontaneously resolves although corticosteroids may hasten the resolution, but it may predispose the patient to develop a relapse of the hepatitis in a study which dealt with atypical clinical manifestation of viral hepatitis in 1992. ${ }^{13,14}$ Therefore, there are still controversies on the efficacy of steroid therapy. However, there might be variable responses depending on the time point of the administration of steroid, and there would be patient groups which might be clinically benefited from steroid treatment with prudent patient selection.

The clinical manifestations of acute cholestatic hepatitis A were presented recently in Korea. In 21 patients, mean value of the peak total bilirubin was $17.2 \mathrm{mg} / \mathrm{dL}$ (range, 11.4-44.9) and the mean time taken for bilirubin to be normalized was 93 days (range, 70-169). The study suggested that that severe cholestasis takes long duration to be improved by supportive care only, considering that most of the patients did not receive corticosteroid or other specific treatment. ${ }^{4}$

In the current cases, despite the symptomatic treatment, all the patients suffered from pruritus, anorexia, and body weight loss. Besides, total bilirubin of $20 \mathrm{mg} / \mathrm{dL}$ or higher was not improved following approximately 4 weeks of conservative in-hospital treatment. Steroid was administered to alleviate their symptoms and shorten the length of hospital stay. Following steroid administration, the level of total bilirubin decreased to half of the pretreatment value within the mean of 14.7 days (range, 8-23), and the prompt response is considered to have reduced the period of hospital stay. However, the overall time period for full recovery might have not been shortened.

Recently, transient elastography is being used to estimate the stages of the hepatic fibrosis in a noninvasive manner. We performed transient elastography in our patients who were in acute phase of viral hepatitis, and it was measured as high as 23.2 $\mathrm{kPa}$ in average. Comparing the mean value of 11.9-13.3 $\mathrm{kPa}$ of the peak liver stiffness in acute hepatitis A patients from the studies we reported previously, ${ }^{15,16}$ it is notable that the patients 
in the current case series showed significantly higher values. Considering that the histopathology showed at most portal or periportal fibrosis in these patients, this marked increase of liver stiffness is thought to have a relationship with the severity of intrahepatic necroinflammation or cholestasis. It was also previously reported that the increased liver stiffness found in patients with acute hepatitis would be related to the severity of the hepatocyte swelling resulted from necroinflammatory process. ${ }^{17}$ However, there is no report demonstrated the increase of liver stiffness in acute viral hepatitis patients with corresponding histopathologic findings to our knowledge. In this sense, our clinical cases have a great value. Liver stiffness decreased in accordance with the stabilization of bilirubin level after treatment, which is a consistent finding with our previous reports. $^{15-16}$

There was no recurrence of hepatitis in all of our three patients. During the administration of prednisolone, there were no complications or adverse events in association with the immunosuppression. It would be mandatory, however, to evaluate the possibility of recurrence of hepatitis following the discontinuation of prednisolone with monitoring of the clinical courses.

Taken together, corticosteroid therapy is effective in improving clinical courses of the patients with cholestatic hepatitis A. Further placebo-controlled studies are also warranted to determine the efficacy of the steroid therapy in patients with cholestatic hepatitis who are refractory to a long-term conservative therapy.

\section{Acknowledgements}

This study was supported by a grant from Ministry for Health, Welfare and Family Affairs, Republic of Korea (No. A050021).

\section{REFERENCES}

1. Jeong SH. Current status and vaccine indication for hepatitis A virus infection in Korea. Korean J Gastroenterol 2008;51:331-337.
2. Sjogren MH. Hepatitis A. In: Feldman M, Friedman LS, Brandt LJ, Sleisenger MH, eds. Sleisenger \& Fordtran's Gastrointestinal and Liver Disease. Vol 2. 8th ed. Saunders, 2006:1639-1644.

3. Jeong SH, Lee HS. Hepatitis A: clinical manifestations and management. Intervirology 2010;53:15-19.

4. Jung KM, Cho YK, Cho JW, Park SH, Kim IH, Choi CS, et al. Clinical features of cholestatic hepatitis with acute viral hepatitis A in Chunbuk province of Korea: Multicenter experience[Abstract]. Korean J Hepatol 2009;15(S3):S175.

5. Coppola N, Genovese D, Pisaturo M, Taffon S, Argentini C, Pasquale G, et al. Acute hepatitis with severe cholestasis and prolonged clinical course due to hepatitis A virus Ia and Ib coinfection. Clin Infect Dis 2007;44:e73-77.

6. Trauner M, Fickert P, Stauber RE. Inflammation-induced cholestasis. J Gastroenterol Hepatol 1999;14:946-959.

7. Wolkoff AW. The hyperbilirubinemias. In: Fauci AS, Braunwald E, Kasper DL, Hauser SL, Longo DL, Jameson HL, eds. Harrison's principles of internal medicine. Vol II. 17th ed. Mc Graw Hill, 2008:1927-1931.

8. Roelofsen H, Schoemaker B, Bakker C, Ottenhoff R, Jansen PL, Elferink RP. Impaired hepatocanalicular organic anion transport in endotoxemic rats. Am J Physiol 1995;269:G427-434.

9. Kauffmann HM, Schrenk D. Sequence analysis and functional characterization of the 5'-flanking region of the rat multidrug resistance protein 2 (mrp2) gene. Biochem Biophys Res Commun 1998;245:325-331.

10. Demeule M, Jodoin J, Beaulieu E, Brossard M, Beliveau R. Dexamethasone modulation of multidrug transporters in normal tissues. FEBS Lett 1999;442:208-214.

11. Sherlock S. Viral Hepatitis; General Features, Hepatitis A, Hepatitis E and Other Viruses. In: Sherlock S, Dooley J, eds. Diseases of the Liver and Biliary System. Oxford: Blackwell Scientific, 2002:272-276.

12. Ware AJ, Cuthbert JA, Shorey J, Gurian LE, Eigenbrodt EH, Combes B. A prospective trial of steroid therapy in severe viral hepatitis. The prognostic significance of bridging necrosis. Gastroenterology 1981; 80:219-224.

13. Schiff ER. Atypical clinical manifestations of hepatitis A. Vaccine 1992;10 Supple 1:S18-20.

14. Dienstag J. Hepatitis A. In: Bircher J, McIntyre N, Rizzetto M, Rodes J, ed. Oxford Textbook of Clinical Hepatology. 2nd ed. Oxford: Oxford University Press, 1999:870-875.

15. Seo YS, Lee KG, Jung ES, An H, Park S, Keum B, et al. Dynamic changes in liver stiffness during the course of acute hepatitis A. Scand J Gastroenterol 2010;45:449-456.

16. Kim JH, Yim HJ, Kim SY, Ahn JH, Jung YK, Joo MK, et al. Changes in liver stiffness after acute or chronic liver injury due to viral hepatitisdoes fibrosis exist after recovery from acute viral hepatitis? Korean J Gastroenterol 2009;54:155-161.

17. Arena U, Vizzutti F, Corti G, Ambu S, Stasi C, Bresci S, et al. Acute viral hepatitis increases liver stiffness values measured by transient elastography. Hepatology 2008;47:380-384. 